\title{
Comparative Study on Flexural Behavior of Steel-Timber Composite beams and Glued Timber I-Beams
}

\author{
Jiejun Wang*, Ying Lu, Yun Lei and Haolei Wang \\ School of Civil Engineering, Central South University of Forestry and Technology, Changsha 410004, China
}

Received 21 October 2020; Accepted 3 December 2020

\begin{abstract}
Shear performance of glued timber I-beam in large-span structures has attracted considerable research attention. Web of glued timber I-beam demonstrating low shear strength parallel to grain is susceptible to cause shear failure in the case of small shear-span ratio. Meanwhile, tensile and compressive strength values of the timber cannot be fully utilized. The use of steel web instead of timber web was proposed in this study to enhance the efficiency of tensile and compressive capabilities of timber, improve bearing capacity of the beam, and change the failure mechanism of timber. A comparative analysis on flexural behavior between steel-timber composite (STC) I-beam with steel web and glued timber I-beam was also incorporated in this study. Six I-beams in two groups were designed in the experiment. Group A included three glued timber I-beams of the same material and group B consisted of three STC I-beams of the same size. Loading mode of three-point bending was used in the bending test of the two groups of specimens. Results show that the failure mechanism of group A is brittle shear failure along the grain while that of group B is steel web yield with shear failure along the grain in the timber flange. Ultimate load, initial stiffness, and strength reserve of group B are higher than those of group A at $79.7 \%, 3.2 \%$, and $140.1 \%$, respectively. The maximum longitudinal compressive strain of top and bottom flanges of specimens in group B is 2.08 and 2.75 times larger than those of group A when the ultimate load is reached. Error between shear strength of glued timber I-beam calculated through Rammer formula and the test result is $4.49 \%$. Hence, the proposed method can successfully utilize tensile and compressive strengths of I-beam timbers.
\end{abstract}

Keywords: steel-timber composite I-beam, glued timber I-beam, flexural capacity, ultimate bearing capacity, shear strength

\section{Introduction}

Compared with traditional rectangular timber beams under the same loading conditions, I-beams demonstrate clear advantages, such as reasonable cross-section shape, high strength-to-mass ratio, and reduced material consumption [1]. Light frame floors and roof systems are widely used in large-span structures. Demand for timber I-beams has gradually increased with the maturation of relevant technologies and specifications. Units have become proactively involved in studies on timber I- and T-beams to improve their application in building structures. OSB glued I-beams are commonly used [2]. Chinese scholar Yang [3] investigated an orthogonally glued timber T-beam, which is theoretically suitable for engineering applications, for their application in actual bridge engineering.

Many studies have been conducted on glued timber Tand I-beams and the results are mainly applied to the building of footbridges. Scholars have explored glued timber $\mathrm{T}$ - and I-beams with different shear-span ratios to expand the application scope of footbridges. The application of glued timber T- and I-beams is remarkably challenging because they experience shear failure along the grain when shearspan ratios are small.

Accordingly, scholars have adopted diverse ways to improve the strength of timber and enhance the shear capacity of timber beams [4-8]. However, comprehensive

*E-mail address: wangiiejun2011@126.com

ISSN: 1791-2377 @ 2020 School of Science, IHU. All rights reserved. doi:10.25103/jestr.136.24 studies on enhancing the overall shear capacity of beams and extending the utilization of the tensile and compressive strength of timber are still needed due to the high cost, unsure durability, and high requirements of the quality and process of adhesives.

On the basis of these studies, this work replaced the timber web with the steel web, connected it with the upper and lower timber flanges to form a steel-timber composite (STC) I-beam, conducted bending test, and provided a reference for the future design of the timber structure.

\section{State of the art}

Scholars have conducted many studies on STC beams. Aiguo Chen [9] investigated the flexural performance of nine STC beams and analyzed impacts of timber plate thickness, thickness and width of the steel beam flange, and height of the web on the flexural capacity of beams. However, durability is uncertain because the steel web and timber beam are cemented. Xuqi Jin [10] explored influence factors of the bearing capacity of an STC beam connected by bolt using numerical simulation and increased the bolt diameter to reduce the stress concentration effectively and improve the shear capacity of the bolt. The bolt diameter is the main factor that affects the bearing capacity of STC beams. Sun [11] used ABAQUS finite element software to carry out nonlinear numerical analysis on the flexural performance of nine H-shaped STC beams and systematically examined key technologies of timber and Hbeam material definition, finite element modeling, spring 
element generation, and postprocessing. But he simply treated the timber as an isotropic material; however, this approach affected the results of finite element simulation to some extent. Cao [12] explored the flexural performance of T-section beam with OSB plate as flange and OSB-steel plate as composite web, established the nonlinear finite element analysis model of T-section ribbed composite beam with steel-OSB plate, and analyzed the impact of the steel plate thickness on the mechanical performance of the composite beam using the finite element model. Su [13] designed and manufactured a full-scale double-web STC beam. The bearing capacity, deformation ability, and failure characteristics of the beam were examined using monotonic loading test. The calculation formula of midspan deflection of the composite beam was deduced according to the test and results of the finite element simulation. However, the test conclusion remains conditional due to inadequate components. Wang [14] conducted a push-out test on STC beams connected by inclined self-tapping screws and provided a new solution to the design of STC beams though the decreased shear stiffness of joints. Yang [15] comprehensively analyzed the influence of the type and diameter of shear connector, spacing, thickness of glued plate, and other factors on the mechanical performance of $\mathrm{H}$ type steel-Larix gmelinii composite beam via push-out tests, but predictions of key parameters in relevant codes were excessively conservative. Hassanieh $[16,17]$ investigated the load-slip behavior and failure mode of STC joined by different types of connectors and effects of shear connectors (e.g., bolts, self-tapping screws, and glue), span, and LVL plate grain orientation (parallel and perpendicular to the grain) with different types and spacings on the structural performance of STC beams. Additionally, Hassanieh established the nonlinear 1D and 2D finite element models of specimens and then compared and verified the models with the test results. To conclude, the results of finite element models were consistent with the test results but failed to explain the minimal effect of using glue combined with mechanical connectors on peak loads of STC beams. Chiniforoush et al. [18] evaluated the long-term behavior of STC joints under sustained load from both experimental and theoretical aspects and considered the change of stiffness caused by moisture content, creep, mechanosorption, and inelastic shrinkage. However, the remarkably large slip value of inelastic shrinkage will require a long period of time for the experimental results to confirm the accuracy of its estimation. Khan [19] developed a kind of C-type STC beam and found that the bearing capacity and seismic performance of the beam can be enhanced by bolt connection in both horizontal and vertical directions without increasing section. Cristiano et al. [20] proposed a new type of STC floor and examined its response under horizontal load and load-transferring performance. Masanori Fujita [21] embedded a hot-rolled I-beam in the rectangular timber beam and connected them with bolts and structural adhesive. The ultimate load, bending strength, and initial stiffness of composite beams with different connection methods were compared, but the accuracy of theoretical calculation values of the bearing capacity of composite beams was insufficient.

These studies investigated the STC beam via experiments and finite element analyses to determine impacts of different parameters on the mechanical performance of the STC beam. However, comparative studies on STC and glued timber I-beams are lacking. An experimental method is used in this study to analyze and compare the failure mode, failure mechanism, bearing capacity, initial stiffness, ductility, and strain of timber flange of STC and glued timber I-beams as well as provide ideas for future designs related to STC beams.

The remainder of this study is organized as follows. The design and loading scheme of specimens are presented in Section 3. The test results and section bearing capacity of glued timber I-beams are discussed in Section 4. Finally, conclusions of this study are summarized in Section 5.

\section{Methodology}

\section{1 Design of specimen}

Three glued timber I-beams (A1-A3) of the same material and size with a total length of 1,500 $\mathrm{mm}$ were designed in group A. Meanwhile, equal spacing stiffeners with a thickness of $30 \mathrm{~mm}$ were set along the span, as shown in Figure 1(a). Group A demonstrates a section height of 150 $\mathrm{mm}$ and each of its five layers was made of Larix gmelinii with a thickness of $30 \mathrm{~mm}$, as shown in Fig. 1(b). Fig. 2(a) illustrates the three specimens (B1-B3) in group B with the same material as group A. Upper and bottom flanges of the specimen were timber plates with a thickness of $30 \mathrm{~mm}$. The middle part was a $90 \mathrm{~mm}$-high steel web. Grade 4.8 ordinary bolts were used to connect the timber flange plate and steel web to form the STC beam. The longitudinal spacing of bolts was $80 \mathrm{~mm}$. In order to reduce the slip, the longitudinal spacing of end bolts was arranged closer. The transverse spacing of bolts and the section size of the I-beam are presented in Figs. 2(b) and 2(c), respectively.

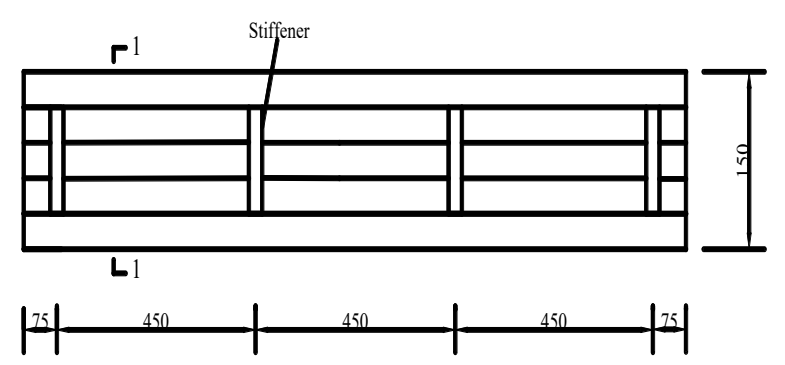

(a) Elevation

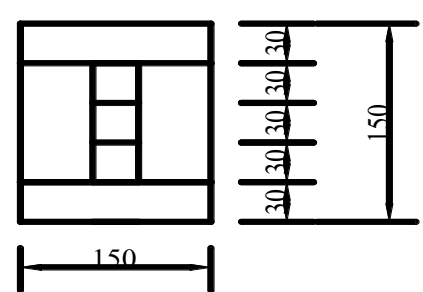

(b) Section 1-1

Fig.1. Dimensions and details of group A 


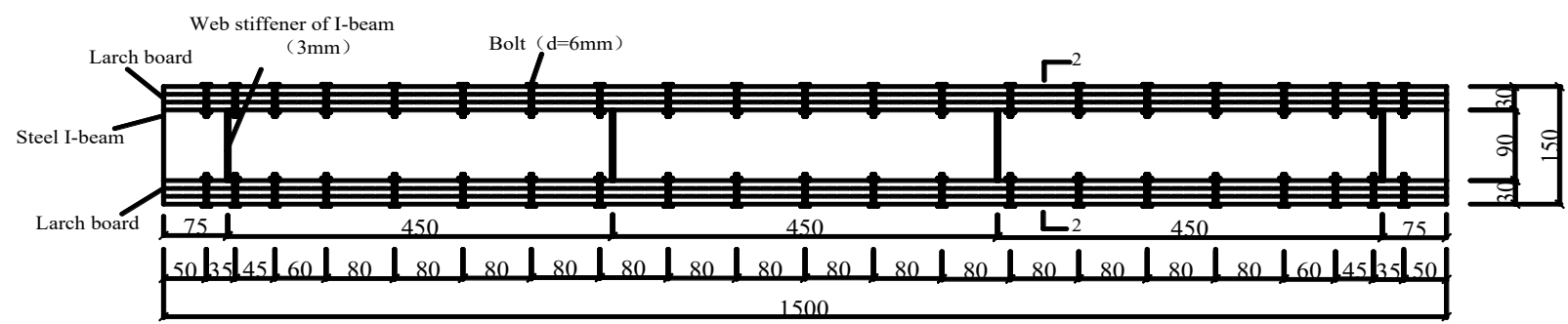

(a) Elevation of group B

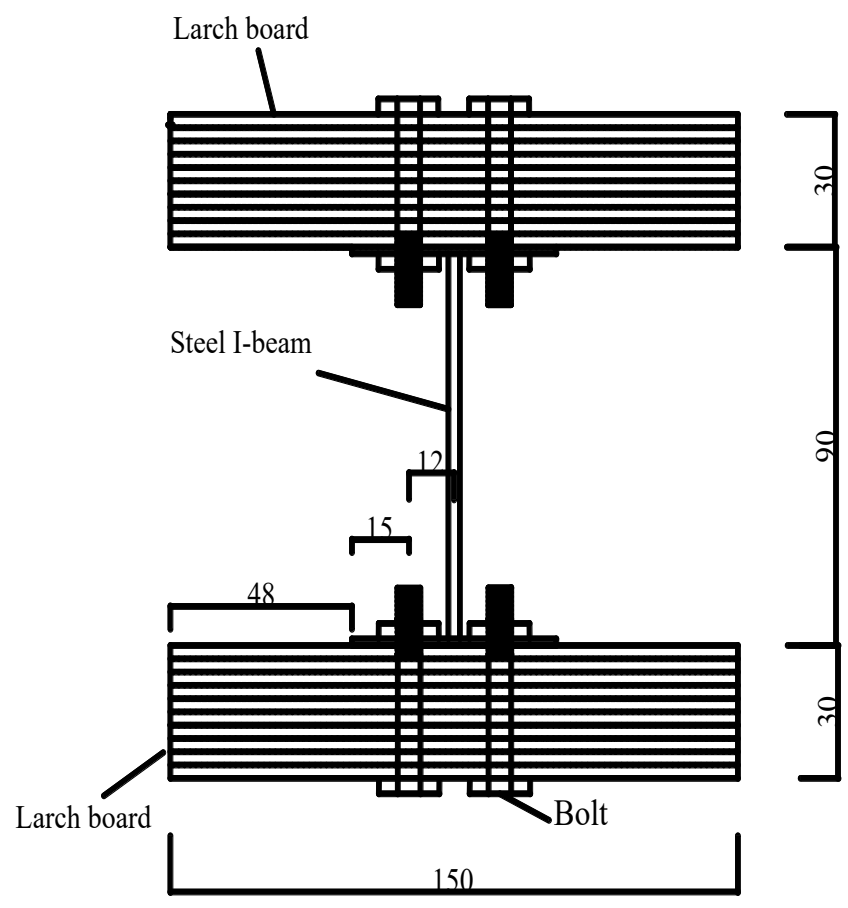

(b) 2-2 section

Fig. 2. Dimensions and details of group B

\subsection{Property of materials \\ (1) Timber}

Flanges of both glued timber and STC I-beams were processed from the sawn timber made of Larix gmelinii with a size of $1,500 \mathrm{~mm} \times 150 \mathrm{~mm} \times 30 \mathrm{~mm}$. The shear strength, shear modulus, and elastic modulus of timber along the grain are listed in Table 1.

(2) Steel

The I-beam was welded using three $3 \mathrm{~mm}$-thick steel plates. The section size, yield strength, tensile strength, and elongation of the steel plate are shown in Table 2.

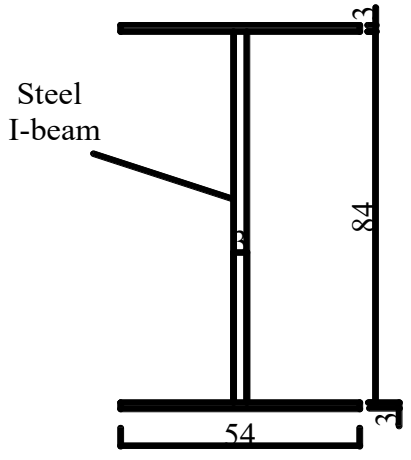

(c) Section of I-beam

Table 1. Properties of timber

\begin{tabular}{c|c|c|c}
\hline Material & $\begin{array}{c}\text { Shear strength parallel to grain } \\
(\mathbf{M P a})\end{array}$ & $\begin{array}{c}\text { Shear modulus } \\
(\mathrm{MPa})\end{array}$ & $\begin{array}{c}\text { Elastic modulus } \\
(\mathrm{MPa})\end{array}$ \\
\hline Larix gmelinii & 11.21 & 839 & 13,320 \\
\hline
\end{tabular}

Table 2. Properties and geometrical dimensions of steel materials

\begin{tabular}{c|c|c|c|c|c|c|c}
\hline $\begin{array}{c}\text { Flange width } \\
(\mathbf{m m})\end{array}$ & $\begin{array}{c}\text { Flange thickness } \\
(\mathbf{m m})\end{array}$ & $\begin{array}{c}\text { Web } \\
\text { height } \\
(\mathbf{m m})\end{array}$ & $\begin{array}{c}\text { Web } \\
\text { thickness } \\
(\mathbf{m m})\end{array}$ & $\begin{array}{c}\text { Yield strength } \\
(\mathbf{M P a})\end{array}$ & $\begin{array}{c}\text { Tensile strength } \\
(\mathbf{M P a})\end{array}$ & $\begin{array}{c}\text { Elongation } \\
\mathbf{( \% )}\end{array}$ & $\begin{array}{c}\text { Elastic } \\
\mathbf{m o d u l u s} \\
(\mathbf{G P a})\end{array}$ \\
\hline 54 & 3 & 84 & 3 & 320 & 455 & 206 \\
\hline
\end{tabular}

Table 3. Properties of adhesive materials

\begin{tabular}{|c|c|c|c|c|}
\hline Coefficient of linear expansion & \begin{tabular}{|c|} 
Minimum cure time at \\
$25^{\circ} \mathrm{C}$
\end{tabular} & $\begin{array}{c}\begin{array}{c}\text { Compressive strength } \\
(\mathrm{MPa})\end{array} \\
\end{array}$ & Tensile strength (MPa) & $\begin{array}{c}\text { Shear strength parallel to } \\
\text { grain (MPa }\end{array}$ \\
\hline $6 \times 10-6 \mathrm{~mm}^{\circ} \mathrm{C}$ & $24 \mathrm{~h}$ & 70 & 30 & 15 \\
\hline
\end{tabular}




\subsection{Loading scheme and arrangement of measuring points}

The experimental loading device and arrangement of measuring point of groups A and B are illustrated in Figs. 3 and 4. According to GB/T50329-2012 Standard for Test Methods of Timber Structures [23], the specimen was supported at both ends and the loading mode was three-point bending. Vertical loads were transferred to specimens through the distribution beam. Preloading of specimens with a value of $20 \%$ of the estimated bearing capacity was required before the formal loading to eliminate the error of the test system and ensure the normal operation of the equipment. The load increment of each stage was $2 \mathrm{KN}$ and the duration of loading of each stage was controlled within 1-2 min during the formal test. Loading was terminated when the specimen was evidently damaged or the load dropped to $80 \%$ of the specimen's bearing capacity.

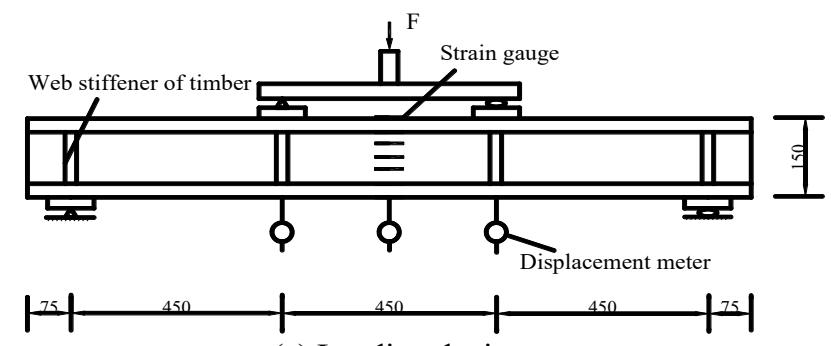

(a) Loading device

Fig.3. Loading device and arrangement of strain gauges of group A

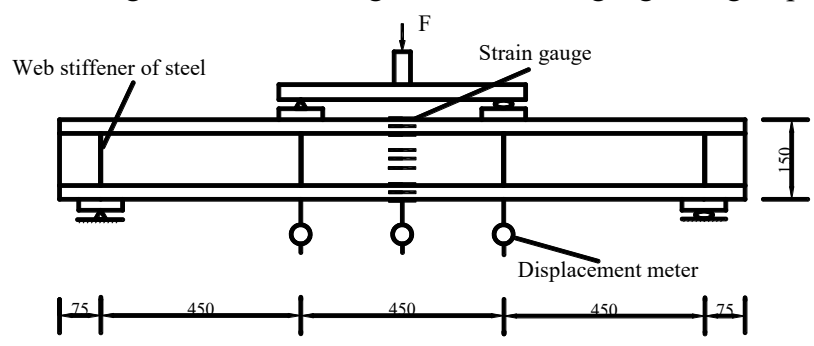

(a) Loading device

Fig.4. Loading device and arrangement of strain gauges of group B
Three displacement meters were arranged at the loading point and below the midspan section of specimens in group A to record the vertical deformation and strain change throughout the entire test, as shown in Fig. 3. Five strain gauges were pasted on the web of midspan section along the height direction, and five strain gauges were placed on the surface of both upper and lower timber flanges. As demonstrated in Fig.4, three displacement meters were arranged at the loading point and below the midspan section of specimens in group B. Three strain gauges were pasted along the height direction of the steel web on the midspan section of the specimen, and three strain gauges were arranged on both upper and lower timber flanges of the midspan section. All measured data were collected via the DHDAS dynamic signal acquisition and analysis system.

\section{Result analysis and discussion}

\subsection{Failure mode}

\section{(1) Specimens in group $\mathrm{A}$}

Failure modes of the three glued timber I-beams in the test were basically the same. The three glued timber I-beams maintained their elastic working from the initial stage of loading to the ultimate load. Glued timber I-beams produced a crisp and subtle sound when the load was increased to $80 \%-90 \%$ of the ultimate load. The specimen suddenly produced out a loud splitting sound and shear cracking occurred parallel to the grain along the span direction when the ultimate load was reached, as shown in Figure 5.

\section{(2) Specimens in group $B$}

Failure modes of the three specimens were basically the same in group B, as shown in Figs. 6-8. The timber near the center of the bottom flange support of the three beams began to crack when the load was between 30 and $40 \mathrm{kN}$ because the relative slip between the timber flange and steel web near the support is the maximum and the deformation of the timber and bolt at the bottom flange is inconsistent. Bolts are squeezed to produce transverse tensile stress on the timber near the bolt and cause cracking of the timber under these circumstances. The timber near the top flange bolt began to suffer shear failure along the grain when the load reached approximately $70 \mathrm{KN}$ because the shear stress distribution of the I-beam flange along the grain direction was nonuniform and the shear stress parallel to the grain near the bolt was the maximum. Cracks near bolts at the top flange continued to expand along the length of the span while the timber near bolts at the bottom flange also began to suffer shear failure along the grain as the load continued to increase. The timber at the bottom flange showed an evident shear crack along the longitudinal direction when the load reached approximately $85 \mathrm{KN}$. The load stopped increasing and the situation was considered to have reached the beam's ultimate load at this time. 

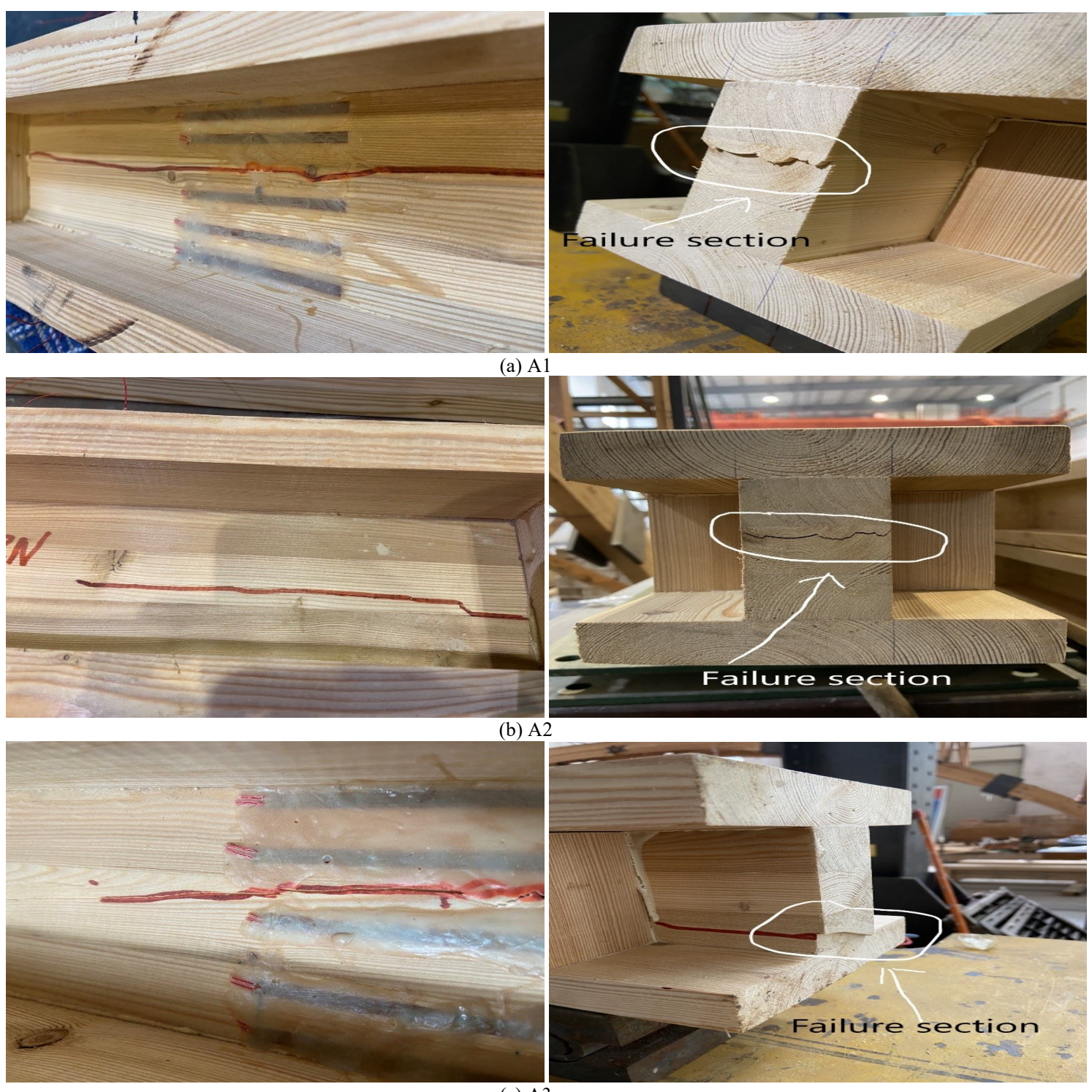

Fig.5. Failure modes of the glued timber I-beam

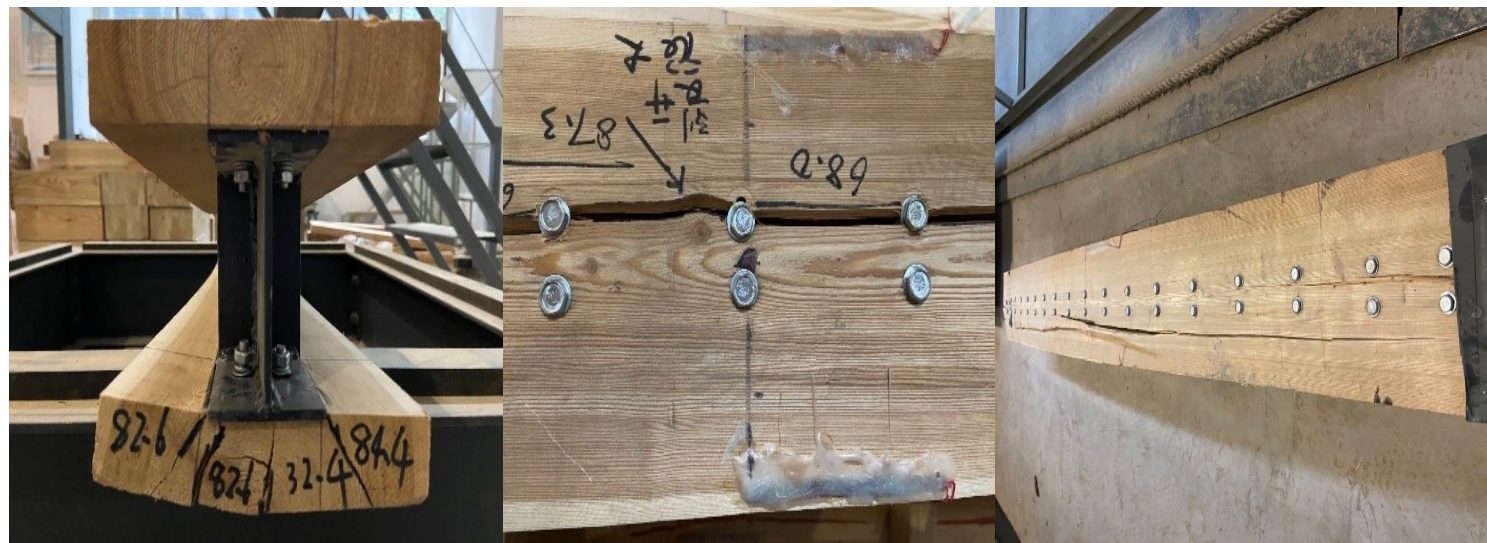

(a) Facade

(b) Top surface

(c) Bottom surface

Fig. 6. Failure mode of B1 


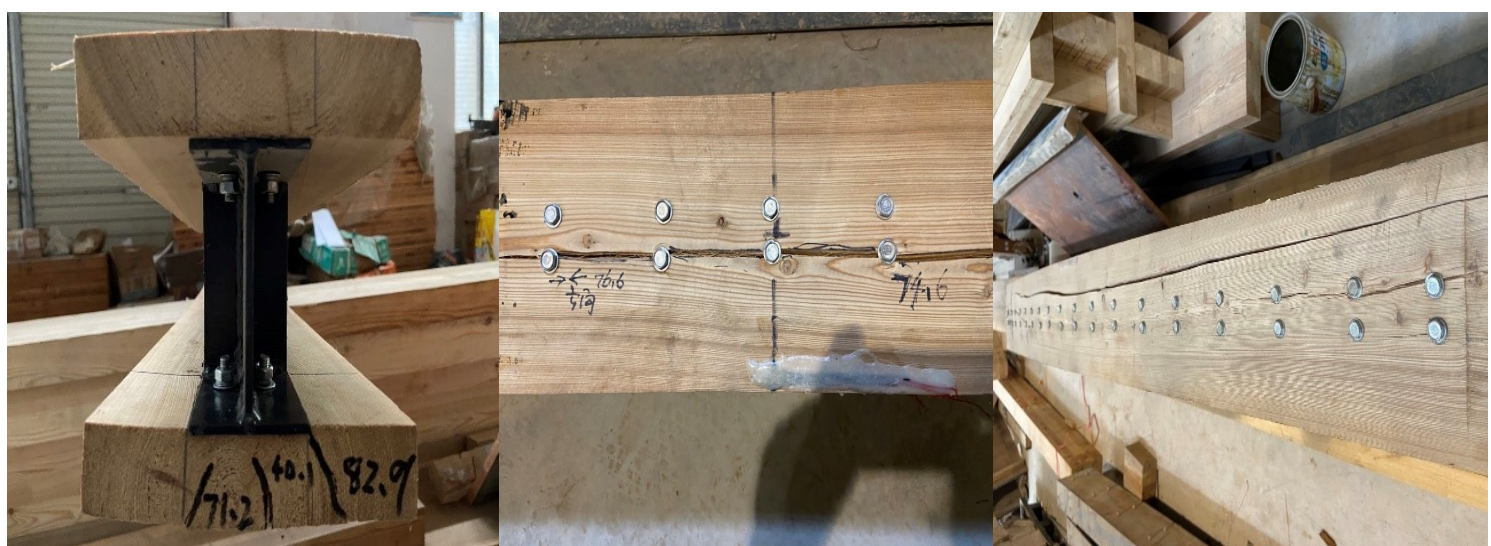

(a) Facade

(b) Top surface

(c) Bottom surface

Fig.7. Failure mode of B2

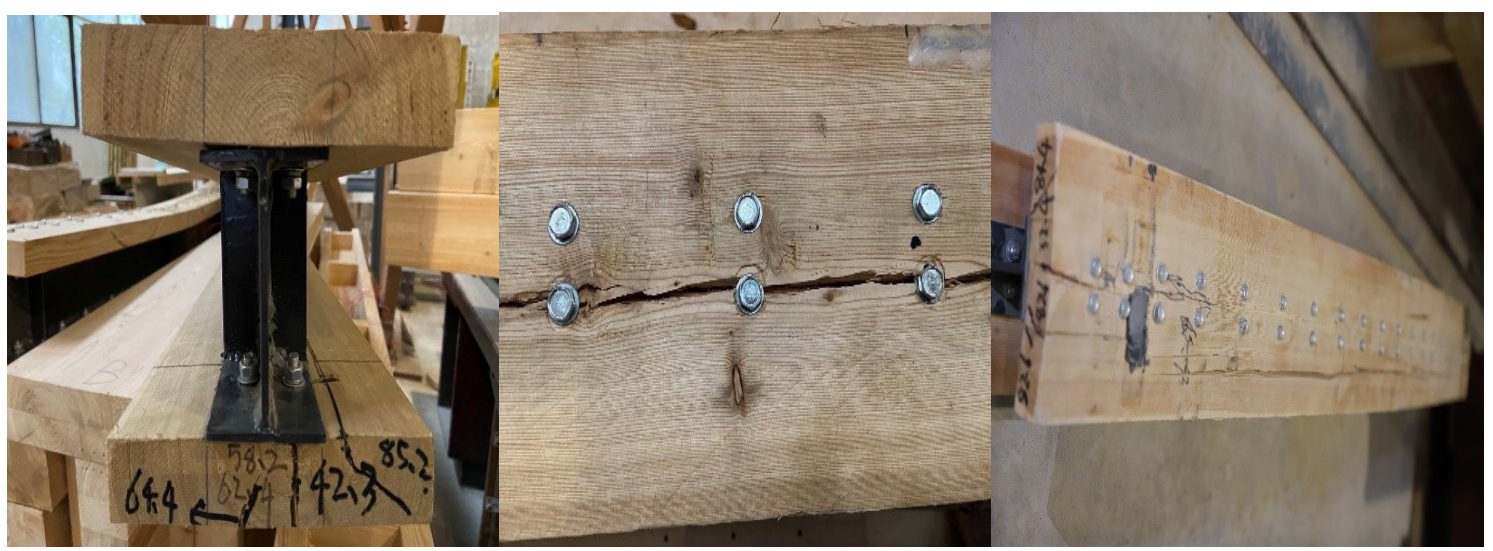

(a) Facade

(b) Top surface

(c) Bottom surface

Fig.8. Failure mode of B3

\subsection{Load-deflection curve}

\section{(1) Specimens in group $A$}

Figure 9 shows the load-midspan deflection curve of group A. Table 4 lists the main test results of group A. Loaddeflection curves of the three glued timber I-beams demonstrate similar slopes and basically change linearly from the initial loading stage to the failure of the specimen. The similar ultimate loads of three specimens indicated that mechanical properties of the three glued timber I-beams are basically the same and the test data can accurately reflect mechanical properties of the structure. Considering the influence of web shear stress on deflection, the total deflection in the midspan can be expressed as the sum of bending deflection and shear deflection when the three-point load is used as follows:

$$
w=\frac{23 p l^{3}}{648 E I}+\int_{0}^{l / 3} \frac{\alpha_{s} V}{G A} d x
$$

where $p$ is half of the applied load, $l$ is the calculated length of span, $E I$ is the bending stiffness of the specimen, $\alpha_{s}$ is the shear coefficient, $V$ is the shear force on the section, $A$ is the section area, and $G$ is the shear modulus in the $\mathrm{L}-\mathrm{R}$ plane. Theoretical calculation values of Equation (1) are shown in Figure 9 and Table 4. $P_{L} / 250$ is the load when the midspan deflection of specimens is $L / 250, P_{u}$ is the ultimate load of specimens, $\beta=\frac{P u}{P_{L / 250}}$, and $\Delta_{u}$ is the midspan deflection when specimens reach the ultimate load.
The theoretical value of the ultimate load is defined as the theoretical loading force that corresponds to the average value of the actual ultimate displacement $(8.0 \mathrm{~mm})$. The theoretical value of ultimate displacement is defined as the theoretical displacement corresponding to the average value of the actual ultimate load. The actual initial stiffness of group A is obtained via linear regression.

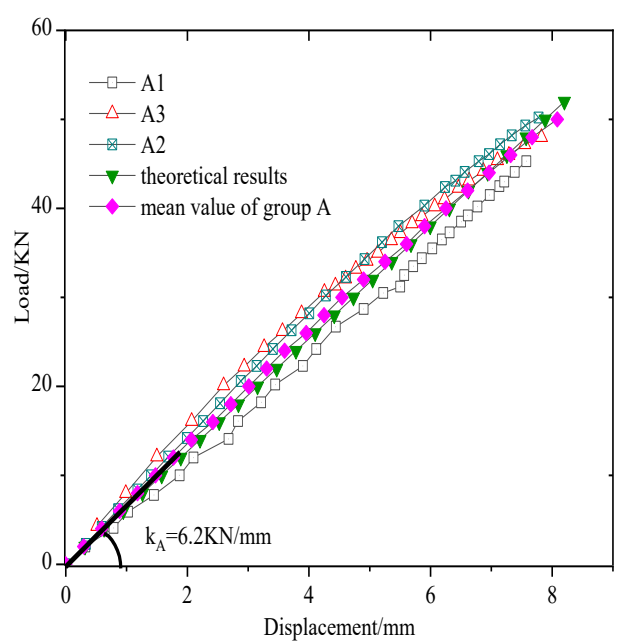

Fig.9. Load-deflection curves of specimens in group A 
Table 4. Experimental results of specimens in group A

\begin{tabular}{|c|c|c|c|c}
\hline Number of test piece & $P_{L / 250} / K N$ & $P_{u} / K N$ & $\beta$ & $\Delta_{u} / \mathrm{mm}$ \\
\hline A1 & 34.2 & 45.3 & 1.32 & 7.55 \\
\hline A2 & 38.0 & 50.2 & 1.32 & 8.67 \\
\hline A3 & 33.2 & 48.0 & 1.46 & - \\
\hline $\begin{array}{c}\text { Relative error between } \\
\text { experimental and } \\
\text { theoretical values }\end{array}$ & 35.1 & 47.8 & 1.37 & - \\
\hline $\begin{array}{c}\text { Average value of the test } \\
\text { Theoretical value }\end{array}$ & 34.2 & -50.7 & -7.48 & 7.00 \\
\hline
\end{tabular}

\section{(2) Specimens in group $B$}

Figure 10 shows the load-midspan deflection curves of group B. Table 5 lists the main test results of group B, $P_{L} / 250$ is the load when the midspan deflection of the specimen is $L / 250, P_{u}$ is the ultimate load of the specimen, $\beta=\frac{P u}{P_{L / 250}}, \Delta_{u}$ is the midspan deflection when the specimen reaches the ultimate load, $P_{y}$ is the load when specimens begin to enter the elastic-plastic stage, $\Delta_{y}$ is the displacement when specimens begin to enter the elasticplastic stage, and $\mu_{\Delta}=\Delta_{u} / \Delta_{y}$ is the ductility coefficient. Specimens in group B undergo elastic and elastoplastic stages. Slopes of load-deflection curves of the three specimens are basically the same in the elastic stage. Stiffness of specimens reduces due to the slip at the junction of the steel web and the timber flange when the load reaches approximately $16 \mathrm{KN}$. Specimens begin to enter the elasticplastic stage when the load reaches around $40 \mathrm{kN}$. The slope of the load displacement curve gradually decreases with the increasing load mainly due to the continuous yielding of the steel web section. The initial stiffness of group B calculated at $6.4 \mathrm{KN} / \mathrm{mm}$ through linear regression is defined as the stiffness of their mean curve before the sliding of group B.

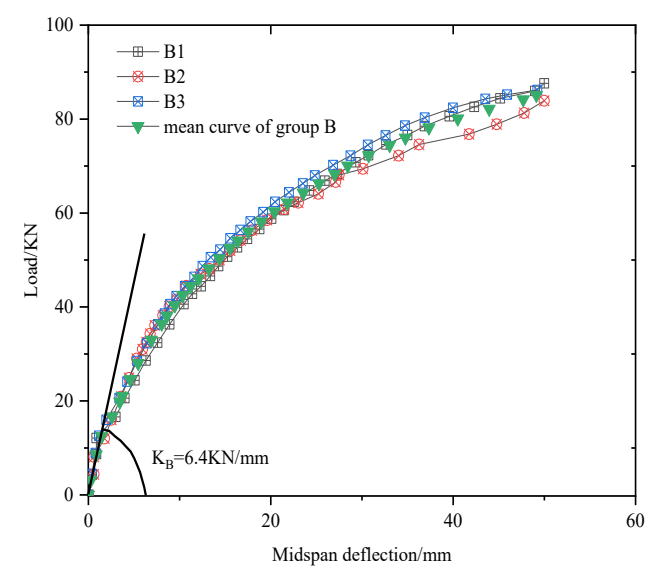

Fig.10. Load-deflection curves of specimens in group B

Table 5. Experimental results of specimens in group B

\begin{tabular}{c|c|c|c|c|c|c|c|c}
\hline $\begin{array}{c}\text { Number of } \\
\text { test piece }\end{array}$ & $P_{L / 250} / K N$ & $P_{y} / K N$ & $P_{u} / K N$ & $\beta$ & $\Delta y / m m$ & $\Delta_{u} / m m$ & $\begin{array}{c}\text { Initial } \\
\text { stiffness }\end{array}$ \\
\hline B1 & 19.8 & 40.6 & 87.6 & 4.42 & 10.47 & 49.99 \\
\hline B2 & 30.1 & 38.2 & 83.9 & 2.79 & 8.16 & 4.77 & - \\
\hline B3 & 28.5 & 42.3 & 86.2 & 3.02 & 9.92 & 49.98 & 4.23 \\
\hline $\begin{array}{c}\text { Average } \\
\text { value }\end{array}$ & 26.1 & 40.4 & 85.9 & 3.29 & 9.52 & 4.96 & 49.73 \\
\hline
\end{tabular}

\section{(3) Comparison of main test results of groups $A$ and $B$}

Part of the test results of groups A and B were summarized to compare their flexural performance, as shown in Table 6 . Although the serviceability limit load of group B is less than that of group A, the ultimate load of group B is $79.7 \%$ higher than that of group $\mathrm{A}$. The $\beta$ value of group $\mathrm{B}$ is $140.1 \%$ higher than that of group A, thereby indicating that specimens in group B demonstrate higher strength reserve after exceeding the serviceability limit state primarily. Because the shear performance of the beam significantly improved and the tensile and compressive properties of both upper and bottom flange timber can be better played after replacing the timber web with the steel web. Ductility was absent because specimens in group A are basically in the linear elastic stage. However, the midspan displacement corresponding to the ultimate load of group B is $521.6 \%$ higher than that of group A because the satisfactory plastic deformation ability of the steel web enables acceptable ductility in the structure of the bottom flange before the fracture. $\mu_{\Delta}$ in Table 6 reflects this point.

Table.6. Comparison of main test results of group A and group B

\begin{tabular}{|c|c|c|c|c|c|c|}
\hline Component & $P_{L / 250} / K N$ & $P_{u} / K N$ & $\beta$ & $\begin{array}{c}\text { Initial stiffness } \\
(\mathrm{KN} / \mathrm{mm})\end{array}$ & $\Delta u / m m$ & $u_{\Delta}$ \\
\hline Group A & 35.1 & 47.8 & 1.37 & 6.2 & 8.00 & - \\
\hline Group B & 26.1 & 85.9 & 3.29 & 6.4 & 49.73 & 5.22 \\
\hline Difference (\%) & -25.6 & 79.7 & 140.1 & 3.2 & 521.6 & - \\
\hline
\end{tabular}

\subsection{Strain distribution of the cross section}

(1) Specimens in group $\mathbf{A}$

Fig. 11 demonstrates the strain of $\mathrm{A} 1, \mathrm{~A} 2$, and $\mathrm{A} 3$ along the section height. Considering the uneven distribution of longitudinal normal stress on the timber flange plate, the average value of five strains that corresponds to the height of $\pm 75 \mathrm{~mm}$ is taken as the strain value in the strain variation diagram. The diagram showed that the position of the neutral 
axis remains the same and the distribution of the strain along the height direction of the timber beam is nearly a straight line with the increasing load. This finding is consistent with the assumption of plane section.

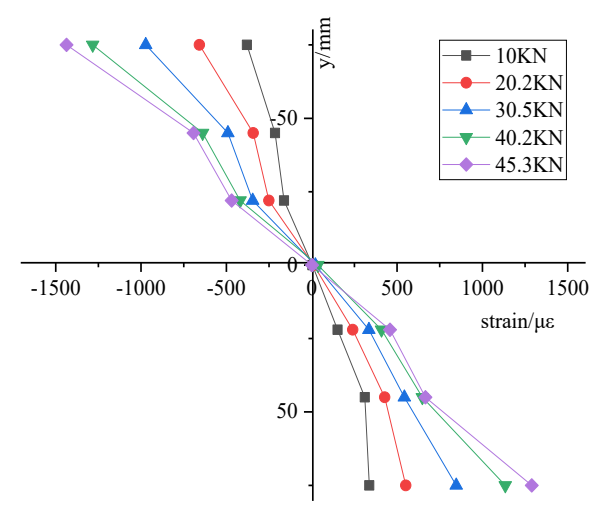

(a) A1

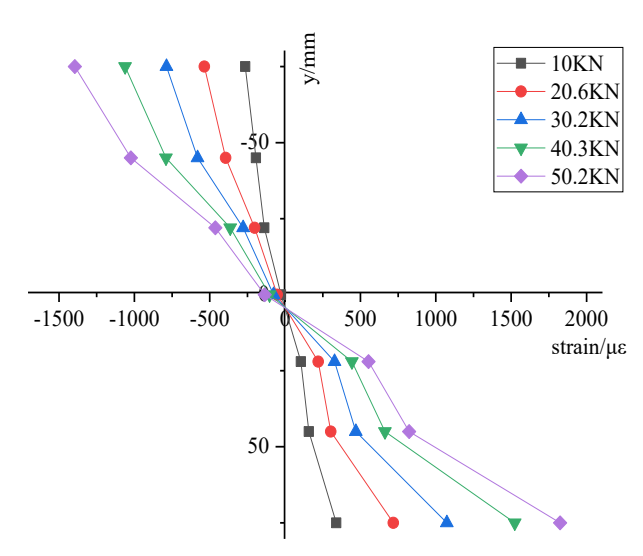

(b) A2

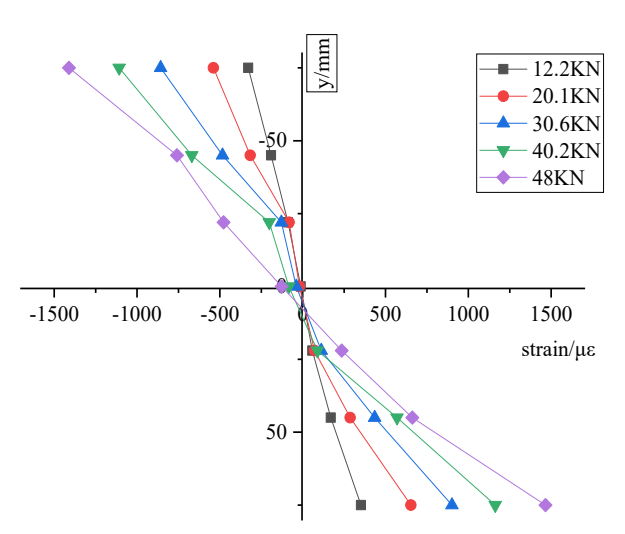

(c) A3

Fig.11. Strain of the midspan section of group A

\section{(2) Specimens in group B}

Strain analysis of the midspan section was conducted because the bending moment of the midspan section is large when group B fails. Figs. 12, 13, and 14 show that the upper and lower timber flanges and steel web are connected by bolts and sliding occurs at their junctions. Hence, the friction at junctions of upper and lower timber flanges and steel web results in asymmetric distribution and development. Specific manifestations are as follows: the compression area of the upper timber flange is larger than the tension area and the tension area of the lower timber flange is larger than the compression area because the friction at the junction makes the upper timber flange bear additional axial compression and the lower timber flange bear additional axial tension. Although the size, boundary condition, load of all specimens, and the bolt connection between both upper and lower timber flanges and the steel web are symmetrical, the distribution and development of the internal force along the height direction of the component are due to the short calculation span of the beam. The beam causes the concentrated load to disturb the stress distribution of the top flange timber where strain gauges are pasted

Specimens no longer satisfy the assumption of plane section at the height of the entire section. A neutral axis exists in each of the upper and lower timber flange and the steel web and their strain changes linearly along their respective neutral axes. Assessment of the strain amplitude of the upper and lower timber flanges and steel web showed that their curvatures are very close although the position of neutral axes of upper and lower timber flanges and steel web is different. Positions of neutral axes change with the increase of load due to the additional axial force generated by sliding at junctions of upper and lower timber flanges and the steel web.

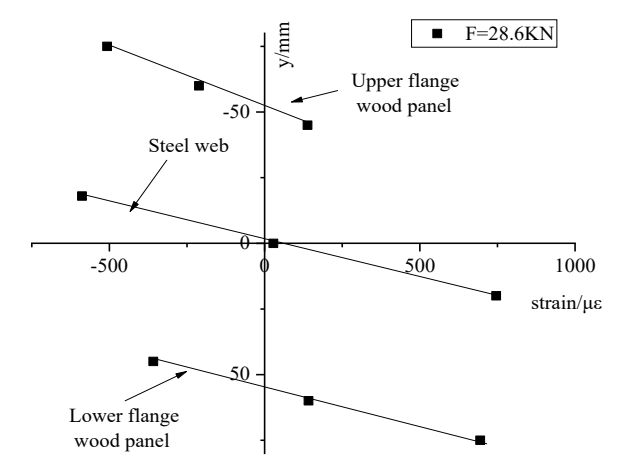

(a) Strain distribution under $1 / 4$ ultimate load

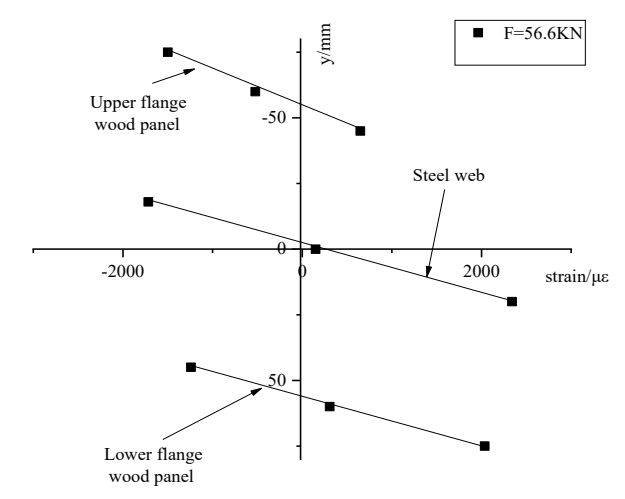

(b) Strain distribution under $1 / 2$ ultimate load 


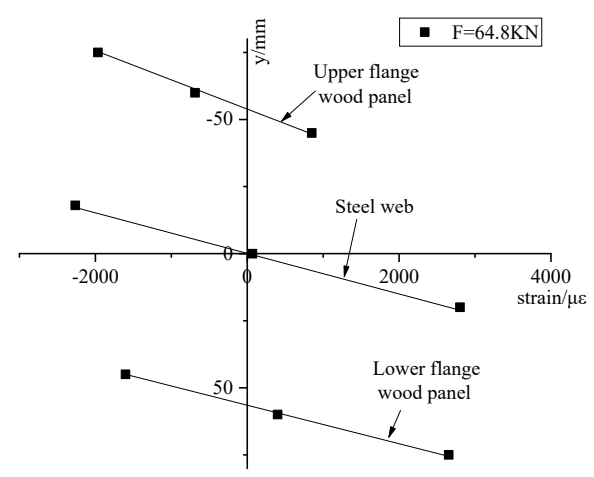

(b) Strain distribution under 3/4 ultimate load

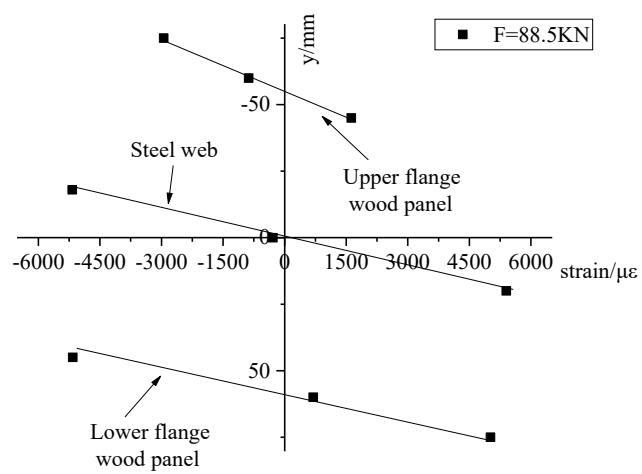

(d) Strain distribution under ultimate load

Fig.12. Distribution of the midspan section strain along the section height of B-1

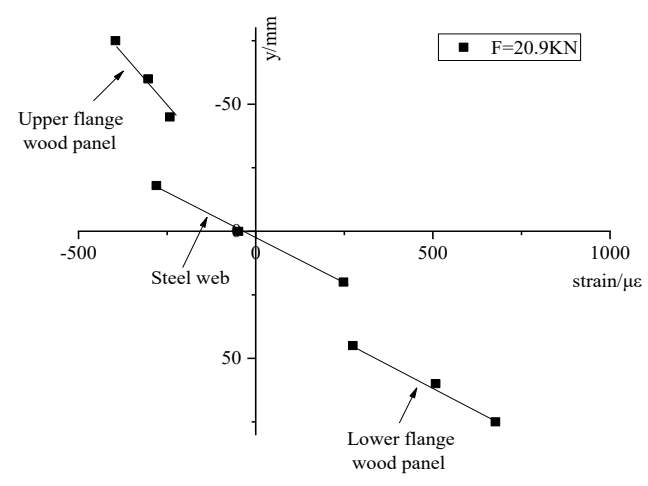

(a) Strain distribution under 1/4 ultimate load

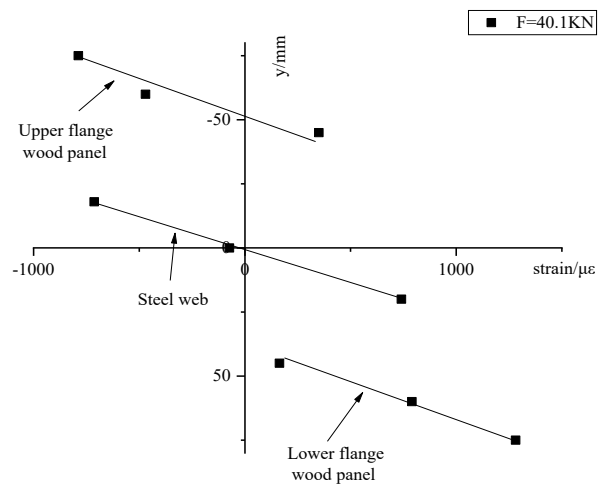

(b) Strain distribution under $1 / 2$ ultimate load

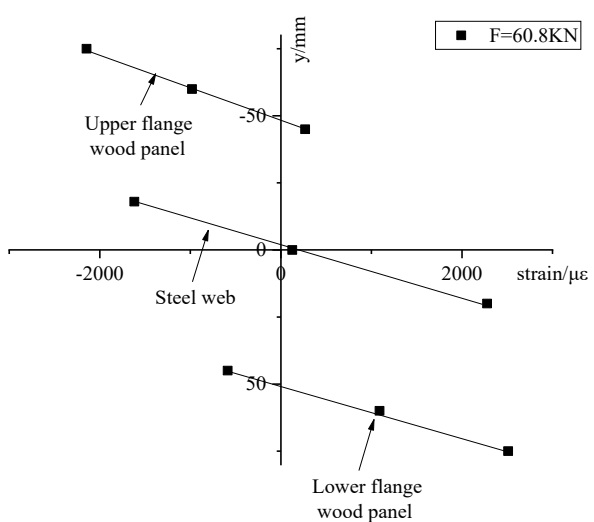

(c) Strain distribution under 3/4 ultimate load

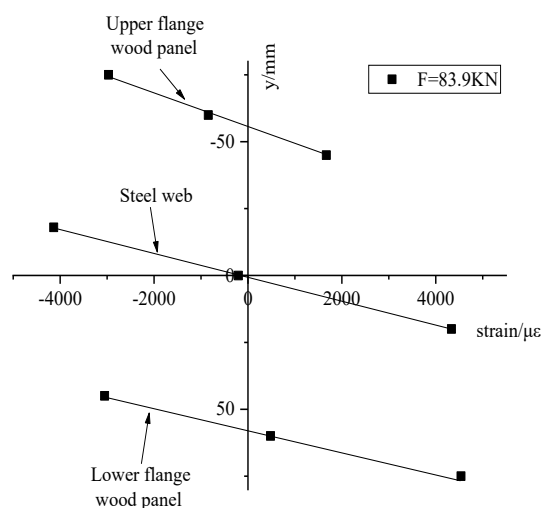

(d) Strain distribution under ultimate load Fig.13. Distribution of the midspan section strain along the section height of B-2

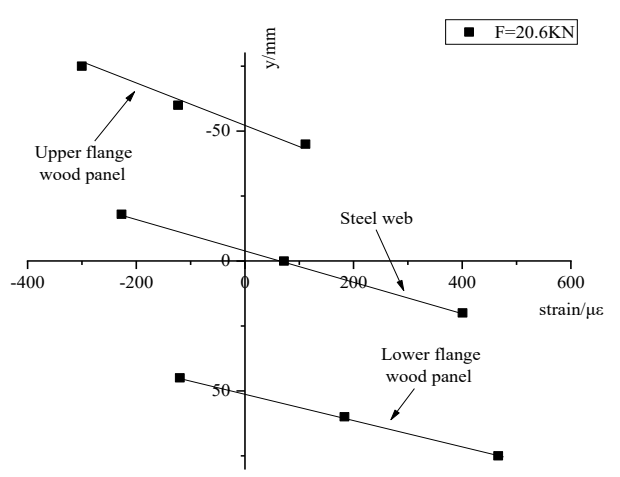

(a) Strain distribution under 1/4 ultimate load

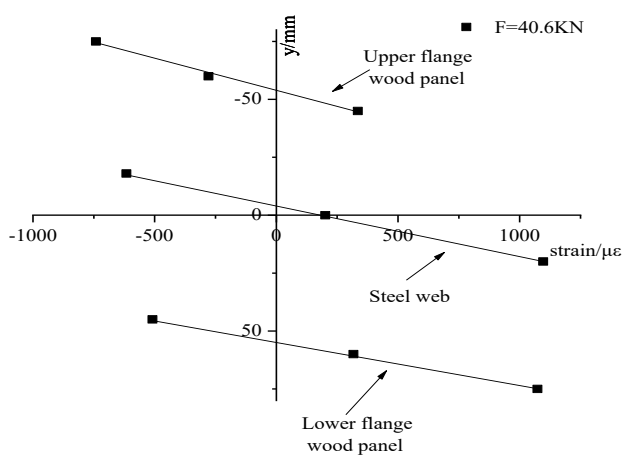

(b) Strain distribution under $1 / 2$ ultimate load 


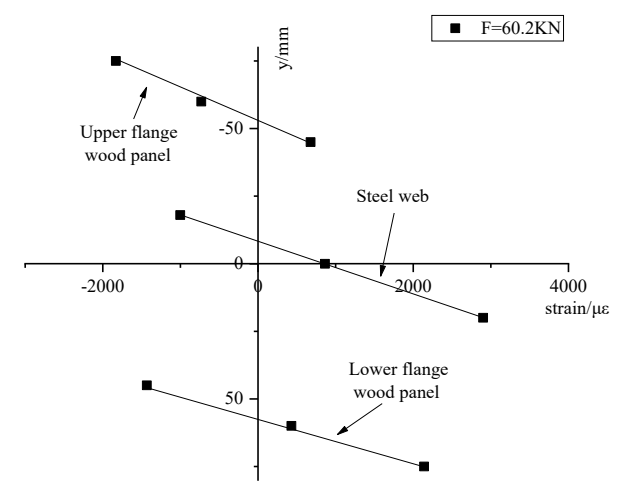

(c) Strain distribution under 3/4 ultimate load

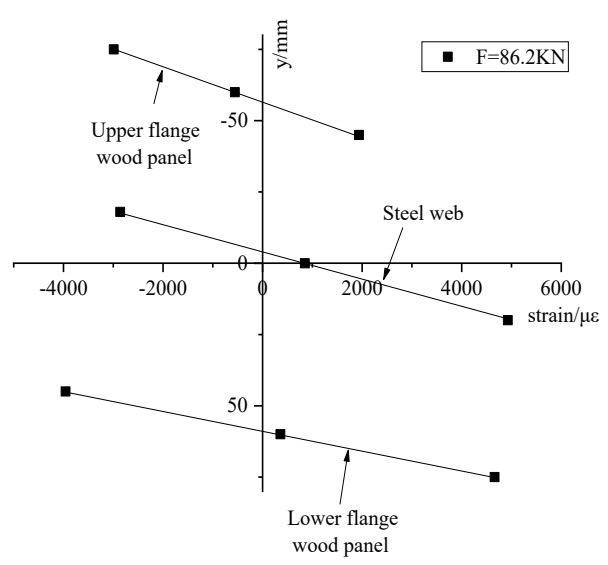

(d) Strain distribution under ultimate load

Fig.14. Distribution of the midspan section strain along the section height of B-3

\section{(3) Comparison of flange timber strain between groups A and $B$}

The longitudinal strain of the timber flange of groups A and $\mathrm{B}$ was compared and the utilization of the timber strength when the two groups reached the ultimate load was analyzed on the basis of the data collected from the tests. As shown in Fig. 15, the maximum tensile stress of the timber flange of group B at 5,015.8 $\mu \varepsilon$ is 2.75 times larger than that of group $\mathrm{A}$ at $1,824.5 \mu \varepsilon$. The maximum compressive stress of the timber flange of group B at 2,989.6 $\mu \varepsilon$ is 2.08 times larger than that of group $\mathrm{A}$ at $1,436.7 \mu \varepsilon$. This finding indicated that replacing timber webs with steel webs can significantly improve the utilization of the timber strength.

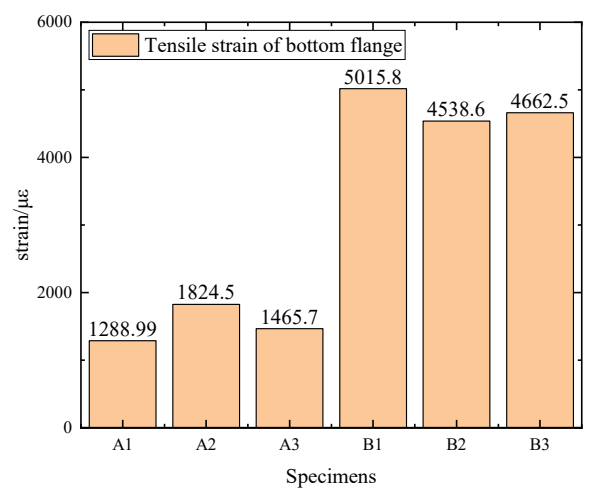

(a) Comparison of maximum tensile stress

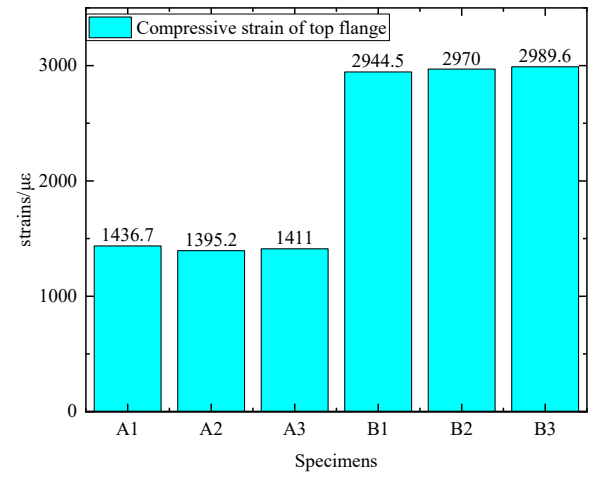

(b) Comparison of maximum compressive stress

Fig.15. Comparison of the strain of flange timber between groups $A$ and B

4.4 Analysis on the bearing capacity of the section

The shear strength of the glued timber beam is related to its size. The relation between the shear strength of the rectangular timber beam and that of the clear timber was calculated using the Rammer formula [24] to obtain the shear strength of the glued timber I-beam as follows:

$\tau=\frac{1.3 C_{f} \tau_{A S T M}}{A_{s}^{\frac{1}{5}}}$

where

$\tau$ is the actual shear strength of the beam,

$C_{f}$ is the stress concentration factor used to adjust the strength of ASTM shear block,

$\tau_{A S T M}$ is the shear strength of the shear block,

$A_{s}$ is the shear area of specimens and expressed as follows:

$A_{s}=\frac{5}{6}\left(2 \times B \times t_{f}\right)$

where $B$ and $t_{f}$ are the width and thickness of the flange, respectively.

Parameters of Equation (2) are summarized in Table 7.

Table 7. Calculation parameters of the actual shear strength of group A

\begin{tabular}{c|c|c}
\hline$\tau_{A S T M} / \mathrm{Mpa}$ & $C_{f}$ & $A_{s} / \mathrm{mm}^{2}$ \\
\hline 11.21 & 2 & 7,500 \\
\hline
\end{tabular}

The actual shear strength of the glued timber I-beam in group $\mathrm{A}$ is $4.89 \mathrm{MPa}$ when parameters of specimens are substituted into Equation (2).

According to the mechanics of materials, the maximum shear stress of the web of the I-beam can be calculated as follows:

$\tau_{\max }=\frac{V}{I t}\left(\frac{b h^{2}}{8}-\frac{b h_{1}^{2}}{8}+\frac{t h_{1}^{2}}{8}\right)$

Where

$V$ is the section shear force at the loading point,

$I$ is the moment of inertia of the section,

$t$ is the width of the web,

$b$ is the width of the flange,

$h$ is the total height of the section,

$h_{1}$ is the height of the web. 
Specific values of parameters are listed in Table 8.

Table 8. Section parameters of glued timber I-beams

\begin{tabular}{|c|c|c|c|c|c|}
\hline$V / N$ & $I / \mathrm{mm}^{4}$ & $t / \mathrm{mm}$ & $b / \mathrm{mm}$ & $\mathrm{h} / \mathrm{mm}$ & $h_{1} / \mathrm{mm}$ \\
\hline 23,900 & $3.58 \times 10^{7}$ & 45 & 150 & 150 & 90 \\
\hline
\end{tabular}

Substituting these parameters into Equation (4) obtains, which is smaller than the result of the Rammer formula. The relative error of $4.49 \%$ is consistent with actual engineering requirements.

The calculation of the bearing capacity of STC beams still requires further investigation due to its complex influencing factors.

\section{Conclusion}

The failure mode, failure mechanism, bearing capacity, initial stiffness, and ductility of trial beams were experimentally and theoretically analyzed using two groups to explore the difference of flexural performance between STC I-beams and glued timber I-beams. The following conclusions can be drawn from this study:

(1) The glued timber I-beam suffered from brittle shear failure along the grain, while the STC I-beam experienced steel web yield with shear failure along the grain in the bottom flange timber.

(2) The ultimate load, ductility, and strength reserve of the STC I-beam are significantly improved when the timber web is replaced with steel web.

(3) The strain of group B is significantly larger than that of group A and its tensile and compressive strength values are fully utilized.

(4) The error between the shear strength of the glued timber I-beam calculated via the Rammer formula and the experimental value is $4.49 \%$, which is consistent with actual engineering requirements.

Flexural properties of three-glued timber and three STC beams were compared in this study from diverse aspects. The results revealed differences in failure mode, failure mechanism, bearing capacity, initial stiffness, ductility, and timber flange stress between the two trial groups. This study can provide a reference for the design of timber and STC structures. Parameters remain unchanged because of the small number of specimens. Impacts of different parameters, such as size of steel web and thickness of timber, on the bearing capacity and tensile and compressive properties of timber can be the foci of future investigations.

\section{Acknowledgments}

This work was supported by the International S\&T Cooperation Program of China (Grant no. 2014DFA53120) and Research on Manufacturing Technology of Modern Glulam Structure of China (Grant no. 9010263203077).

This is an Open Access article distributed under the terms of the Creative Commons Attribution License

\section{References}

1. Wang, C. M., Wang, G., Xu, L. Y., Cui, Y. J., "Design and verification test methods of the bending stiffness and the coefficient of shear deflectio of timber I-joist". Forestry and Grassland Machinery, 25(03) ,2014, pp. 5-7+21.

2. Racher, P., Bocquet, J. F., Bouchair, A., "Effect of web stiffness on the bending behaviour of timber composite I-beams". Materials \& Design, 28(3), 2007, pp.844-849.

3. Wang, J. J., Yang, T., Ning, F., Rao Z. Y., "Bending Capacity of Orthogonal and Parallel Glued timber T-section Beams". Journal of Engineering Science and Technology Review, 13(1), 2020, pp.8697.

4. Schober, K. U., Harte, A. M., Kliger, R., Jockwer, R., Xu, Q. F., Chen, J. F., "FRP reinforcement of timber structures". Construction and Building Materials, 97, 2015, pp.106-118.

5. Ling, Z. B., Liu, W. Q., Shao, J. S., "Experimental and theoretical investigation on shear behaviour of small-scale timber beams strengthened with Fiber-Reinforced Polymer composites". Composite Structures, 240, 2020, pp. 111989.

6. Svecova, D., Eden, R. J., "Flexural and Shear Strengthening of Timber Beams Using Glass Fiber Reinforced Polymer Bars: An Experimental Investigatio". Canadian Journal of Civil Engineering, 31(1), 2011, pp. 45-55.

7. Burgers, T. A., Gutkowski, R. M., Balogh, J., Radford, D. W., "Repair of full-scale timber bridge chord members by shear spiking". Bridge Engineering, 13(4), 2008, pp. 310-318.

8. Shaun, H., Kenton, T., Dagmar, S., Baidar, B., "Effectiveness of GFRP Sheets for Shear Strengthening of Timber". Journal of Composites for Construction, 10(6), 2006, pp. 483-491.

9. Chen, A. G., Li, D. H., Fang, C., Zheng, Q. G., Xing, J. H., "Experimental study on flexural behavior of H-shaped steel-timber composite beams". Journal of Building Structures, 37(S1), 2016, pp. 261-267.

10. Jin, X. Q., Bai, Y. S., Xu, G. L., “Analysis of Influencing Factors on Bearing Capacity of Thin-Walled Steel-Timber Composite Beams Connected by Bolts". Journal of Southwest Forestry University(Natural Sciences), 38(04), 2018, pp. 167-172.
11. Sun, H. Y., Bai, L. B., Li, D. H., "Numerical simulation and parameter analysis of flexural behavior of H-shape steel-timber composite beams". Building Structure, 47(13), 2017, pp. 51-56.

12. Cao, B. Z., Liu, H., Zeng, X., Zhu, C. R., Li, Y., "Research on flexural behavior of steel sheet-OSB composite T-beam with lateral OSB ribs". Journal of Building Structures, 39(11) 2018, pp. 112$118+157$.

13. Su, Z., Cao, B. Z., Dong, J. S., "Experimental study and finite element analysis of double-belt steel-timber composite beams". Natural Science Journal of Hainan University, 38(04), 2020, pp.111

14. Wang, C. L., Lyu, J. F., Zhao, J., Yang, H. F., "Experimental investigation of the shear characteristics of steel-to-timber composite joints with inclined self-tapping screws". Engineering Structures, 215, 2020, pp. 110683.

15. Yang, R. Y., Li, H. T., Lorenzo, R., Ashraf, M., Sun, Y. F., Yuan, Q., "Mechanical behaviour of steel timber composite shear connections". Construction and Building Materials, 258, 2020, pp. 119605.

16. Hassanieh, A., Valipour, H. R., Bradford, M. A., "Load-slip behaviour of steel-cross laminated timber (CLT) composite connections". Journal of Constructional Steel Research,122, 2016, pp. 110-121.

17. Hassanieh, A., Valipour, H. R., Bradford, M. A., "Experimental and numerical study of steel-timber composite (STC) beams". Journal of Constructional Steel Research, 122, 2016, pp. 367-378.

18. Chiniforush, A. A., Valipour, H. R., Bradford, M. A., Akbarnezhad, A., "Long-term behaviour of steel-timber composite (STC) shear connections". Engineering Structures, 196, 2019, pp. 109356.

19. Khan, M. S., Prof, N. S., Pawar, Y. P., "Timber-Steel-Composite Beams for Framed Structure". International Journal of Engineering Research \& Technology, 8(6), 2019, pp. 1330-1335.

20. Loss, C., Frangi, A., "Experimental investigation on in-plane stiffness and strength of innovative steel-timber hybrid floor diaphragms". Engineering Structures, 138, 2017, pp. 229-244.

21. Fujita, M., Iwata, M., "Bending Test of the Composite Steel-Timber Beam". Applied Mechanics and Materials, 351-352, 2013, pp. 415421. 
22. Tang, Z., Xiao, Y., "Experimental study on mechanical behavior of glue laminated bamboo I-joists". Journal of Building Structures, 38(09), 2017, pp. 138-146.

23. Zuo, H. L., Wang, D. Y., He D. P., Wang, Y. B., "Performances of Glued-laminated Timber in the Compressive Zone of Prestressed Glulam Beams". Journal of Northeast Forestry University, 42(06), 2014, pp. 90-94+107.
24. Rao, Z. Y., Ning, F., Li, J. Z., Wang, J. J., "Experimental Study on Bending Behavior and Finite Element Simulation Analysis of Glued Timber Inverted T-beam". Journal of Engineering Science and Technology Review, 13 (1), 2020, pp. 147-159. 